\title{
USM3D Predictions of Supersonic Nozzle Flow
}

\author{
Melissa B. Carter ${ }^{1}$, Alaa A. Elmiligui ${ }^{2}$, and Richard L. Campbell ${ }^{3}$ \\ NASA Langley Research Center, Hampton, VA 23681 \\ and \\ Sudheer N. Nayani ${ }^{4}$ \\ Analytical Services \& Materials, Inc., Hampton, VA 23666
}

\begin{abstract}
This study focused on the NASA Tetrahedral Unstructured Software System CFD code (USM3D) capability to predict supersonic plume flow. Previous studies, published in 2004 and 2009, investigated USM3D's results versus historical experimental data. This current study continued that comparison however focusing on the use of the volume souring to capture the shear layers and internal shock structure of the plume. This study was conducted using two benchmark axisymmetric supersonic jet experimental data sets. The study showed that with the use of volume sourcing, USM3D was able to capture and model a jet plume's shear layer and internal shock structure.
\end{abstract}

\section{Nomenclature}

$d \quad=$ diameter of the jet exit, inches

$p \quad=$ pressure

$p_{e} \quad=$ jet exit pressure

$p_{\text {inf }} \quad=$ freestream pressure

$p_{0} \quad=$ total pressure

$\mathrm{x}=$ distance in the stream-wise direction, inches

$\mathrm{y}^{+} \quad=$ dimensionless wall distance

$z=$ distance in the waterline direction, inches

$\Delta p \quad=\left(\mathrm{p}-\mathrm{p}_{\text {inf }}\right)$

\section{Introduction}

A s part of the NASA Fundamental Aerodynamics Program High-Speed Project, evaluation and improvement of

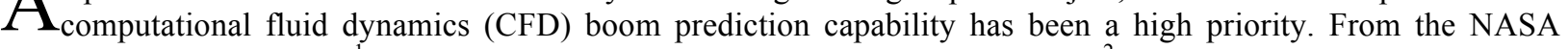
Boom Workshop of $2008^{1}$ to the more recent AIAA Boom Workshop of $2014^{2}$, numerous conditions and CFD codes have been examined and compared. As this work has continued, researchers began looking into different components of supersonic flight. One of the remaining questions is how does the engine's plume effect the boom signature? Although this is a goal for the High-Speed Project, the more intermediate question became, can unstructured codes properly capture the plume? Structured grids have historically provided the necessary gridding structure to capture the sheer layer from the jet flow. ${ }^{3}$ Unstructured grids with proper shear layer cell distribution have proved more difficult to create. ${ }^{4}$

This study focused on the NASA Tetrahedral Unstructured Software System (TetrUSS). ${ }^{5}$ This system utilizes a variety of sources to provide some control of field grid placement. In particular, the recently developed volume sources have been successfully used to control grid density and orientation in a number of applications. Previous

1 Aerospace Engineer, Configuration Aerodynamics Branch, Mail Stop 499, AIAA senior member.

2 Research Engineer, Configuration Aerodynamics Branch, Mail Stop 499, AIAA senior member.

${ }^{3}$ Senior Research Engineer, Configuration Aerodynamics Branch, Mail Stop 499, AIAA Associate Fellow.

${ }^{4}$ Senior Scientist, CFD Group, 107 Research Drive, AIAA Senior Member. 
studies, published in $2004^{6}$ and $2009^{7}$, investigated TetrUSS's results versus historical experimental data. The current study continued the comparison, however, focusing on the use of the volume souring to capture the shear layers and internal shock structure of the plume. The study was conducted using two benchmark axisymmetric supersonic jet experimental data sets that are described in section III.

\section{CFD Code Information}

This CFD study used the NASA TetrUSS for all the computations. This CFD suite, created and maintained by NASA Langley Research Center, includes an unstructured grid generation program called VGRID, a post-processor named POSTGRID, and the flow solver USM3D. ${ }^{5}$

VGRID is an interactive, or batch, tetrahedral unstructured grid generation program. The grids produced by VGRID are suitable for computing Euler or Navier-Stokes flow solutions. The grid spacing is related to the strength of user-defined sources placed in the domain. The methodology is based on the Advancing-Front method (AFM) ${ }^{8}$ and the Advancing-Layers method (ALM). ${ }^{9}$ Both techniques are based on marching processes in which tetrahedral cells grown on an initial triangular boundary mesh and gradually form in the field around the geometry. Once the advancing front process is completed in VGRID, an additional post-processing step is required using POSTGRID to close any open pockets and to improve grid quality.

In 2008, a new version of VGRID was introduced. ${ }^{10}$ Software updates to VGRID included growth rates, surface sources, and volume sources. The outer boundary sources were no longer required for grid growth rates. The outer boundary sources were replaced with a user specified growth rate of the grid that dictates how the grids grow outwards from the aircraft and their maximum size. Additionally, new volume source types became available in VGRID. In the older version of VGRID, only point and line sources were available. Now, users can define sources that are based on a sphere, a cylinder, or a cone.

The USM3D code ${ }^{11}$ is a cell-centered, finite-volume Navier-Stokes flow solver that uses Roe flux-difference splitting ${ }^{12}$ to compute inviscid flux quantities across the faces of the tetrahedral cells. Several options for turbulent closure are available: the one-equation Spalart-Allmaras (S-A) model ${ }^{13}$ (with and without a wall function), and several two-equation models, including Menter's Shear Stress Transport (SST) model. ${ }^{14}$ The minmod limiter, used for supersonic conditions, was used during this study to ensure numerical stability. For the USM3D CFD cases conducted in this study, the k-e Sarkar PD turbulence model was used. ${ }^{15}$ This turbulence model has done well for supersonics jets. ${ }^{15}$ The USM3D 2004 results, that are used for comparison later, use an older version of the turbulence model.

Previous published results from the CFD codes FUN3D ${ }^{16}$ and Wind-US ${ }^{17}$ are included for comparison with the second axisymmetric nozzle case. Further information on these cases can be found in those references.

\section{Experimental Data}

Two benchmark, axisymmetric supersonic jet experimental data sets were used for this study. The first set, was from J.M. Seiner ${ }^{18}$ and was obtained at the NASA LaRC Jet Noise Laboratory. The data for the axisymmetric nozzle was obtained at Mach 2 at the jet exit and a Reynolds number of $1.3 \times 10^{6}$, based on model jet exit diameter. This data has become a benchmark for evaluating CFD and consequently, this report will use past USM3D results for additional comparison. Unfortunately, the image in Seiner's paper of the test set-up is not clear in digital form so was not included in this paper. The CFD definition of the nozzle is shown in Fig. 1.

The second data set was from L.E. Putnam ${ }^{19}$ and was obtained at the NASA LaRC $4 \times 4$ foot supersonic pressure tunnel. The data for the nozzle was obtained at Mach 2.2 and a Reynolds number of $1.86 \times 10^{6}$ based on model maximum diameter of $15.24 \mathrm{~cm}$. This data has also become a benchmark for comparing CFD. However, for this case, comparisons will be shown among USM3D, FUN3D ${ }^{16}$ and Wind-US. ${ }^{17}$ Figure 2, from Ref. 12, shows the test set-up of the Putnam jet nozzle for the experiments, while Fig. 3 shows the nozzle definition used (nozzle 6). ${ }^{19}$

\section{Sourcing Methodology}

In order to capture the plume and other flow characteristics properly, it is very important to source the nozzle configurations adequately and appropriately. For example, the cell spacing, distribution, and source divergence angle needs to be correctly defined to capture the shear layer. Adequate cell density is also needed to accurately capture the core length and the shock diamonds. The present study has also revealed the importance of proper grid resolution of the nozzle lip to be able to capture the shear layer correctly. 
A novel sourcing method for the axisymmetric type of nozzles (e.g. Seiner and Putnam nozzles) has been incorporated into an automated grid generation process known as R2D that utilizes the Q2D code. ${ }^{20,21}$ The R2D process begins with the new A2D code, which reads a simple coordinate definition of the nozzle geometry, several flow variables, and source control parameters from an input file, computes source locations and sizes, then writes out the input files required by VGRID to generate a 2-D, unstructured grid for the nozzle. For the current study, additional volume sources were added to $\mathrm{A} 2 \mathrm{D}$ in an attempt to better resolve the flow in the exhaust shear layer and plume regions. After the 2-D grid is generated by VGRID, it is fed into the Q2D code, where prismatic cells are extruded from the triangular faces of the 2-D grid. This layer of prisms is then split into the tetrahedral cells required for analysis in USM3D. The Q2D code was originally developed for airfoils, but has recently been extended to include axisymmetric configurations ${ }^{20}$ and grids for sonic boom analysis. ${ }^{21}$ For the quasi-2D grids used in this study, one-cell wide "pie-slice" grids were generated using a radial angle increment of 10 degrees.

Figure 4 shows the sourcing for the Seiner nozzle in the symmetry plane. The A2D code places a total of five cylindrical sources for the nozzle and the field and one line source at the nozzle lip. The lip source ensures that enough cells are placed across the lip thickness and also for proper grid blending with the shear layer. Cylindrical source 1 covers the nozzle length and ensures enough grid density inside the nozzle. The cylindrical source 2 starts at the exit plane of the nozzle extending into the plume area and is sufficiently long enough to cover the plume core. The cylindrical sources 1 and 2 are defined as solid (inner radius is zero). The cylindrical sources 3 and 4 are defined in such a way as to capture the expansion of the shear layer. These are defined as conical and annular with the inner radius equal to that of the outer radius of cylindrical source 2. The definition (input value) of the semi-cone angle of the conical sources is extremely important in properly capturing the shear layer and thus the total pressure and total temperature distributions in the plume core. Semi-cone angles varying from 2 to 10 degrees have been tested for this nozzle and these conditions with good results for an angle of 5.71 degrees corresponding to an expansion rate of 10 percent. Using this expansion rate, the fine mesh generated by cylindrical source 4 closes to meet the nozzle centerline at just under 6 nozzle diameters downstream of the lip (see Fig. $5, x=0$ is at the jet exit). The cylindrical source 5 starts at the end of cylindrical source 4 and extends into the field to cover the entire plume. It also ensures that enough grid points are defined in the exit far field boundary. The same volume sourcing strategy for the nozzle and plume was used for the Putnam nozzle, but two volume sources were added to enclose the body to ensure adequate grid density on its outer surface.

\section{Results}

Since the Seiner nozzle is axisymmetric, a quasi-axisymmetric computational grid was generated as a 10-degree slice that contained 814,145 cells. The grid was fully viscous, resolved to the walls, with the first cell height sized to obtain an $\mathrm{y}+$ of 0.5 . The grids were run computationally until convergence of at least 3 orders in the residual of the L-2 norm was obtained. The runs were conducted at a freestream Mach number of 0.1 , a nozzle pressure ratio (NPR) of 7.82, and total temperature 563 R. Figure 6 shows the overall grid for the case, while Fig. 7 shows the Mach profile. The volume sourcing has captured at least six of the plume internal shocks as seen in Figs. 7 and 8. Figure 9 compares the computational grids from the past two USM3D studies with the current grid. The 2004 study grid had 85,817 grid cells, whereas the 2009 study grid had 300,750 cells (when all grids were cut to the same 10 degrees). Figure 10 compares the Mach profiles of the three cases. As can be seen, the 2014 results better capture the sheer layer and the internal structure of the plume. Although there is a definite improvement from the 2004 to 2009 results, the 2014 results have a crisper shear layer definition and internal plume Mach structure. Figure 11 compares the Mach profile with the experimental data taken by Seiner. The 2009 and 2014 both do an excellent job of matching the experimental data.

Next, the Seiner nozzle was run under-expanded $\left(\mathrm{p}_{\mathrm{e}} / \mathrm{p}_{\mathrm{o}}=1.445\right)$. The characteristic humps of the shear layer of the plume are clearly seen in Fig. 12, while the internal shock structure is more evident in Fig. 13. Figure 14 compares the CFD results with experimental data. Although the CFD results do not consistently match the amplitude of the experimental data, it does match the location of each of the peaks. The results shown are for the 5.71 degree source semi-cone angle as discussed in section IV. The other cone angles investigated showed worse correlation.

The Putnam nozzle's computational grid was a 10-degree slice that contained 1,259,430 cells (approximately 231,088 nodes) and is shown in Fig. 15. The grid was fully viscous, resolved to the walls, with the first cell height sized to obtain an $y+$ of 0.5 . The grids were run computationally until convergence of at least 3 orders in the residual of the L-2 norm was obtained. The Putnam nozzle's runs were conducted at a freestream Mach number of 2.2, a total temperature of $563 \mathrm{R}$, and an NPR of 8.12. As mentioned, the FUN3D results were compared with USM3D results. FUN3D uses an adjoint method to move and stretch the grid as needed to capture the flow 
characteristics that are not know a priori. A discrete adjoint solution is computed based on a pressure based sonic boom sensor cost function, integrated over a cylindrical surfaces centered at the model. Additional details of the grid adaptation method used in FUN3D are given in Ref. 16. Figure 16 compares the original FUN3D grid with the FUN3D adjoint grid and the USM3D grid. FUN3D is node-based flow solver, but converted to cells, the original grid was approximately 315,614 cells, (57,910 nodes) whereas the adjoint grid was approximately 2,878,946 cells (528,247 nodes) (when all grids were cut to the same 10-degree slice). As mentioned, FUN3D uses an adjoint-driven adaptation method to cluster grid points, whereas USM3D utilized the volume source approach to cluster grid points in pre-determined regions. Figure 17 compares the p/pinf profile of the three grids near the nozzle lip. Even though the USM3D grid was just less than half the size of the final FUN3D grid, the USM3D results are as crisp as the adjoint results and capture the high pressure point following the initial pressure low traced down from the nozzle lip.

Results from Wind-US are also compared to USM3D results. Wind-US 2.0 was used for the solutions shown and was run with a modified second-order Roe upwind scheme for stretched grids. Additional details concerning the code and results are given in Ref. 17.

Figure 18 compares the pressure differential from FUN3D, Wind-US, and USM3D with the experimental results where $\mathrm{x}=0$ is the jet exit. Both FUN3D and USM3D match the data better than Wind-US. While there are minor differences between the USM3D and FUN3D results, both predict the approximate shock strength and location. Figure 19 shows the plume shear layer and internal shock structure as predicted by USM3D for the freestream Mach number of 2.2 and NPR of 8.12. Figure 19a shows Mach contours, while Fig. 19b shows the pressure contours on the symmetry plane of the Putnam nozzle. The symmetry plane density gradient is shown in Fig. 19c. In these figures, the structure of the shear layer and shock diamond pattern can be clearly seen in the USM3D results.

\section{Conclusion}

In this study, the NASA Tetrahedral Unstructured Software System CFD code (USM3D) was used to compute the supersonic nozzle jet flow for two benchmark test cases. For the Seiner nozzle, computations were conducted for a freestream Mach number of 0.1 and NPR of 7.82, while, for the Putnam nozzle, the freestream Mach number was 2.2 and NPR of 8.12. The two-equation k-e model with compressibility correction of Sarkar was used for all computations. Computations confirmed that USM3D could predict the general jet shear layer and shock diamond structures in compressible flow when adequate grids are used. Some details, such as shock diamond peak amplitudes, are still under-predicted and require further investigation to resolve discrepancies. Overall, computed results compared well with classical data in the literature and in the case of the Putnam nozzle, with previously published FUN3D and Wind-US results.

Improvements in the grid sourcing capability and techniques of VGRID provided USM3D with the capability to resolve the jet's plume shear layer and internal shock structure. The present study revealed the importance of proper grid resolution of the nozzle lip to be able to capture the shear layer correctly. In addition, the current study showed that in order to capture the plume and jet flow characteristics, it is imperative to source the nozzle configurations adequately. The cell spacing, distribution, and source divergence angle needs to be correctly defined to capture the shear layer. Sufficient grid density must be provided in the mixing region. Adequate cell density is also needed to capture the core length and the shock diamonds. In summary, for jet plume analysis, high grid density is required in high velocity gradient regions in the shear layer and in high-pressure gradient regions near shock fronts. Future work by the authors involves studying plume shock interaction and how it affects sonic boom signature.

\section{Acknowledgments}

The work done was sponsored by the NASA Fundamental Aeronautics Program High Speed Project. The majority of the computational runs and grid generations were conducted by Sudheer Nayani of Analytical Services \& Materials, Inc. under contract. 


\section{References}

${ }^{1}$ Park, M.; Aftosmis, M; Campbell, R.L.; Carter, M.B.; Cliff, S.; and Bangert, L.: "Summary of the 2008 NASA Fundamental Aeronautics Program Sonic Boom Prediction Workshop." AIAA-2013-649, January 2013.

2 "1st AIAA Sonic Boom Prediction Workshop." 1st AIAA Sonic Boom Prediction Workshop. AIAA, n.d. Web. 02 May $2014<$ http://lbpw.larc.nasa.gov/>.

${ }^{3}$ Abdol-Hamid, K.S.; Pao, S.P.; Hunter, C.A.; and Deere, K.A.: "PAB3D: Its History in the Use of Turbulence Models in the Simulation of Jet and Nozzle Flows." AIAA 2006-489, January 2006.

${ }^{4}$ Pao, S.P.; Abdol-Hamid, K.S.; Campbell, R.L.; Hunter, C.A.; Massey, S.J.; and Elmiligui, A.A: "Unstructured CFD and Noise Prediction Methods for Propulsion Airframe Aeroacoustics." AIAA 2006-2597, May 2006.

${ }^{5}$ Frink, N. T.; Pirzadeh, S.Z.; Parikh, P.C.; Pandya, M.J.; and Bhat, M.K, "The NASA Tetrahedral Unstructured Software System", The Aeronautical Journal, Vol. 104, No. 1040, October 2000, pp. 491-499.

${ }^{6}$ Abdol-Hamid, K.S.; Frink, N. T.; Deere, K.A.; and Pandya, M.J.: "Propulsion Simulations Using Advanced Turbulence Models with the Unstructured-Grid CFD Tool, TetrUSS.” AIAA 2004-714, January 2004.

${ }^{7}$ Pandya, M.J.; Abdol-Hamid, K.S.; and Frink, N. T.: "Enhancement of USM3D Unstructured Flow Solver for High-Speed High-Temperature Shear Flows.” AIAA 2009-1329, January 2009.

${ }^{8}$ Lohner R and Parikh P., "Three-Dimensional Grid Generation by the Advancing Front Method." Int.J.Num.Meth. Fluids 8, pp 1135-1149 (1988).

9 Pirzadeh S., "Three-dimensional unstructured viscous grids by the advancing layers method." AIAA Journal, Vol. 34, No. 1, January 1996, pp. 43-49.

${ }^{10}$ Pirzadeh S., "Advanced Unstructured Grid Generation for Challenging Aerodynamics Applications." AIAA2008-7178, August 2008.

${ }^{11}$ Frink, N. T., "Three-Dimensional Upwind Scheme for Solving the Euler Equations on Unstructured

Tetrahedral Grids", Ph. D. Dissertation, Virginia Polytechnic Institute and State University, September 1991.

${ }^{12}$ Roe, P., "Characteristic Based Schemes for the Euler Equations." Annual Review of Fluid Mechanics, Vol. 18, 1986, pp. 337-365.

${ }^{13}$ Spalart, P.; and Allmaras, S.A., "One-equation turbulence model for aerodynamic flows." AIAA 92-0439, January 1992.

${ }^{14}$ Menter, F.R., "Improved Two-Equation k-omega Turbulence Models for Aerodynamic Flows." NASA TM103975, October 1992.

${ }^{15}$ Pandya, M.J.; Abdol-Hamid, K.Z.; and Frink, N. T., "Enhancement of USM3D Unstructured Flow Solver for High-Speed High-Temperature Shear Flows.” AIAA-2009-1329, January 2009.

${ }^{16}$ Park, M. A.; Carlson, J. R.: “Turbulent Output-Based Anisotropic Adaptation.” AIAA Paper 2010-0168, January 2010.

${ }^{17}$ Castner, R. S., "Analysis of Plume Effects on Sonic Boom Signature for Isolated Nozzle Configurations," AIAA Paper 2008-3729, June 2008.

${ }^{18}$ Seiner, J. M.; Dash, S. M.; and Wolf, D. E.: "Analysis of Turbulent Underexpanded Jets, Part II: Shock Noise

Features Using SCIPVIS.” AIAA J., vol. 23, no. 5, May 1985, pp. 669-677.

${ }^{19}$ Putnam, L. E. and Capone, F. J., "Experimental Determination of Equivalent Solid Bodies to Represent Jets Exhausting into a Mach 2.20 External Stream.” NASA-TN-D-5553, Dec. 1969.

${ }^{20}$ Elmiligui, A.A.; Fredericks, W.J.; Guynn, M.D, and Campbell, R.L., "Numerical Investigation of Fuselage Boundary Ingestion Propulsion Techniques." AIAA Paper 2013-4402, August 2013.

${ }^{21}$ Nayani, S.; and Campbell, R.L., "Evaluation of Grid Modification Methods for On- and Off-Track Sonic Boom Analysis." AIAA Paper 2013-0798, January 2013. 


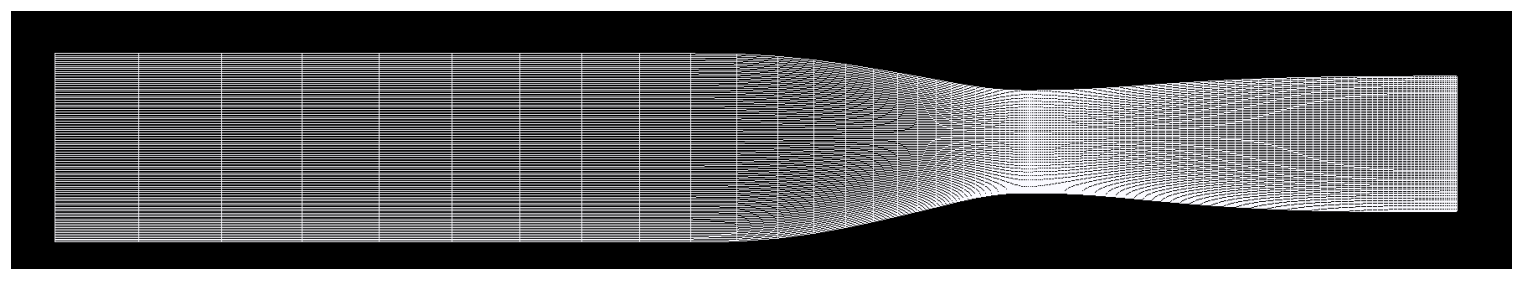

Figure 1. Seiner Nozzle Computational Definition.

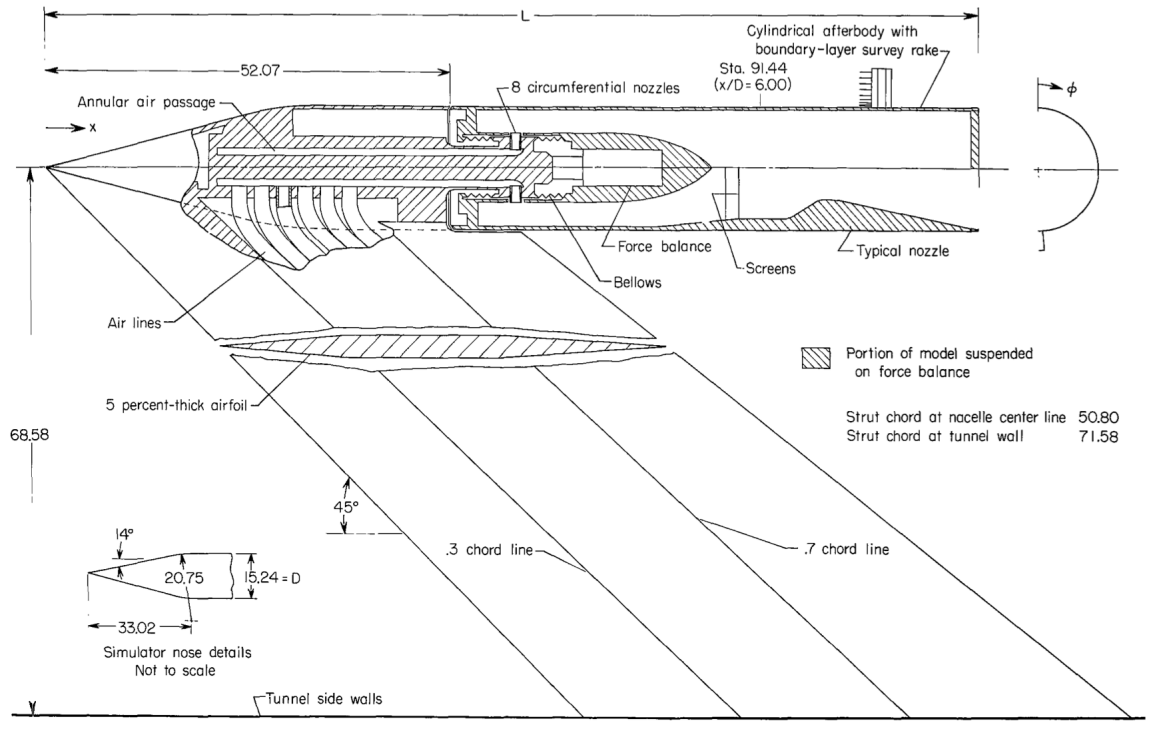

Sketch of jet-engine exhaust-nozzle simulator. All dimensions in centimeters unless othervise noted.

Figure 2. Putnam experimental set-up. ${ }^{19}$

American Institute of Aeronautics and Astronautics 


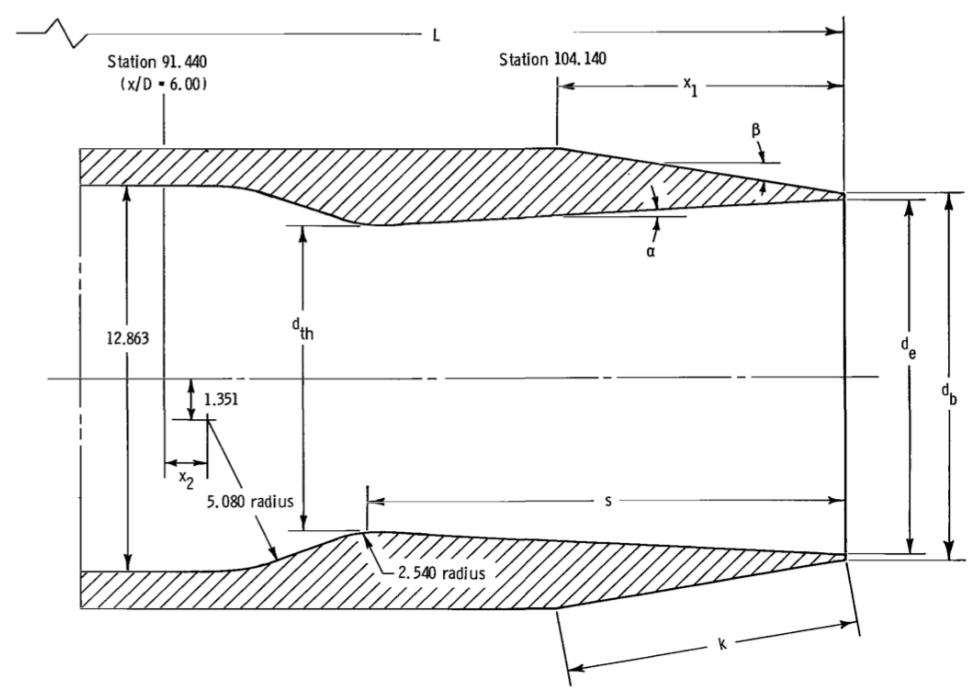

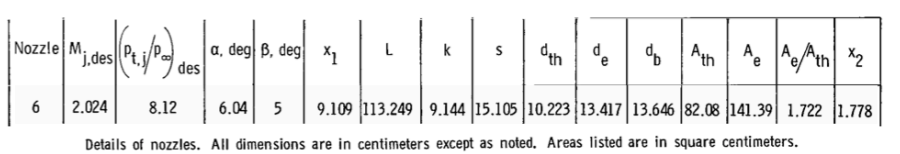

Figure 3. Putnam nozzle definition. ${ }^{19}$

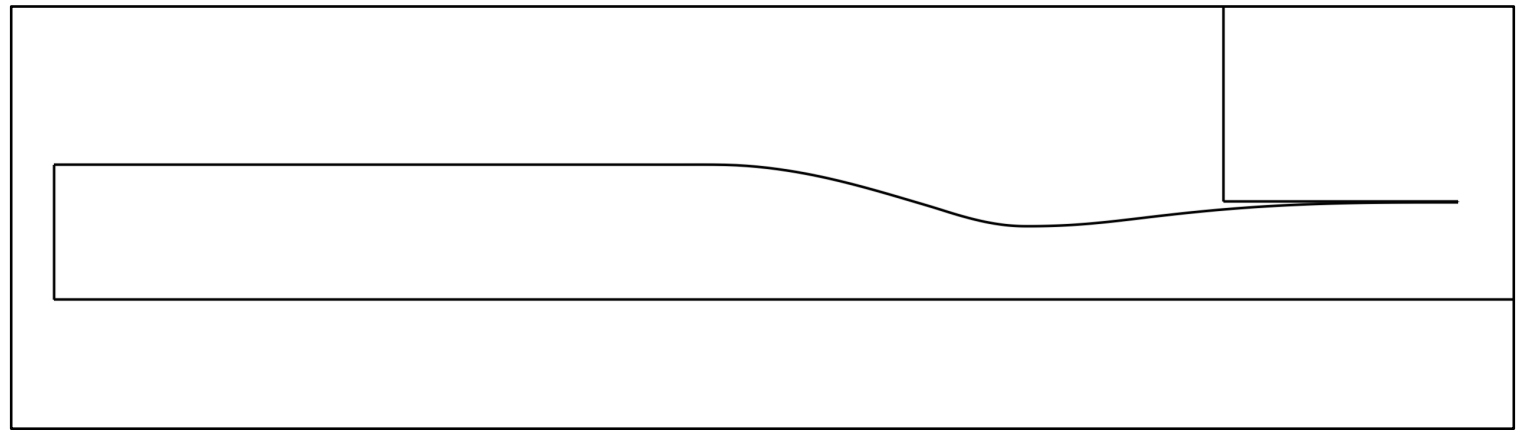

a) Seiner nozzle configuration.

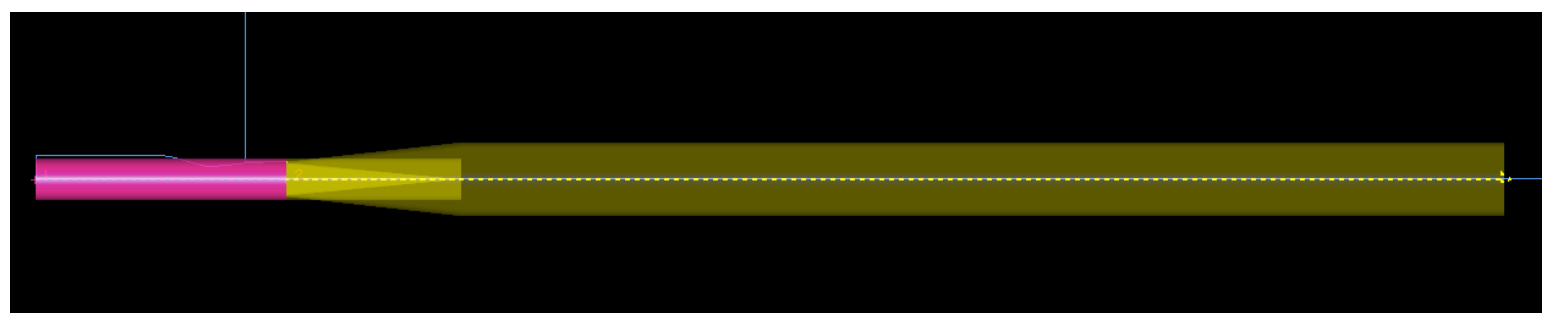

b) Seiner nozzle volume sourcing.

Figure 4. Seiner nozzle configuration and sourcing.

American Institute of Aeronautics and Astronautics 


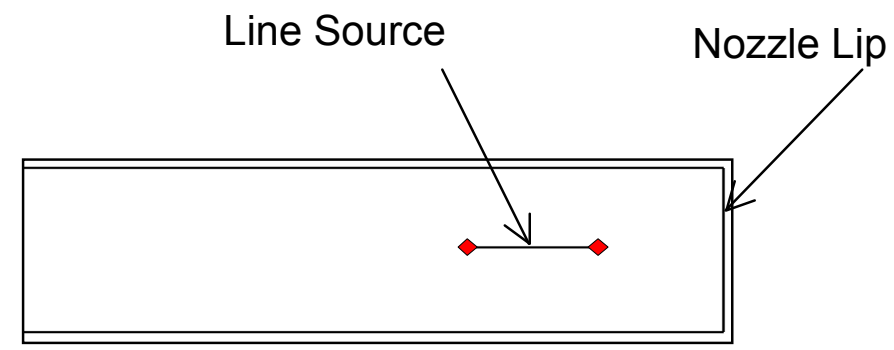

c) Nozzle lip line source.

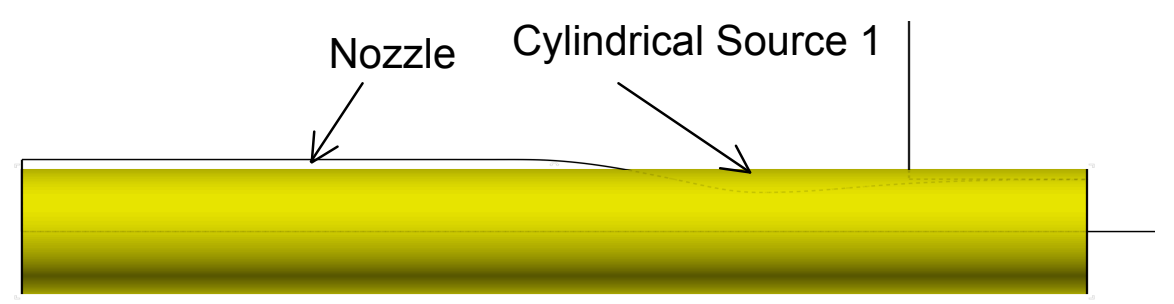

d) Cylindrical source 1.

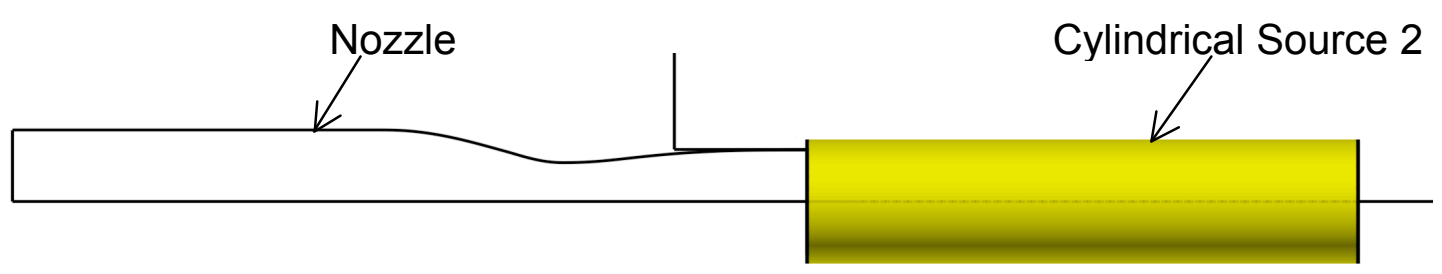

e) Cylindrical source 2.

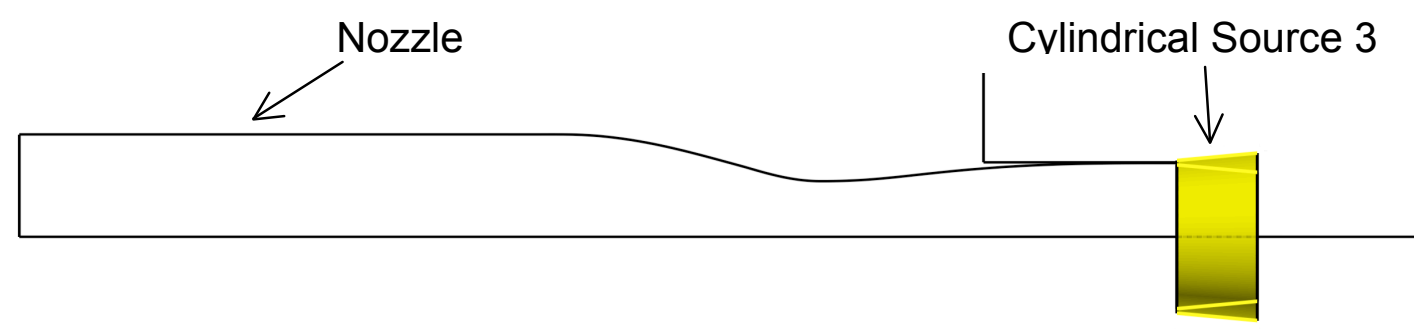

f) Cylindrical source 3 .

Figure 4. Seiner nozzle configuration and sourcing - continued. 


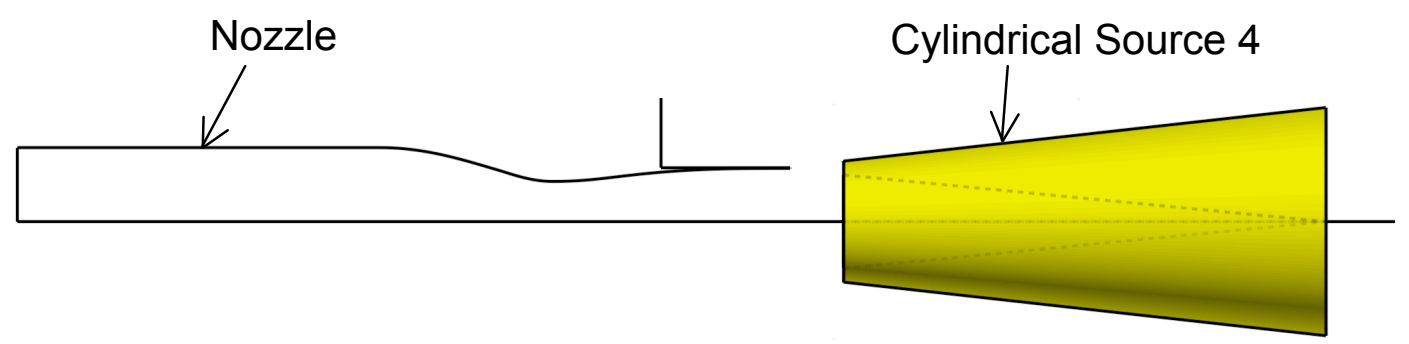

g) Cylindrical source 4.

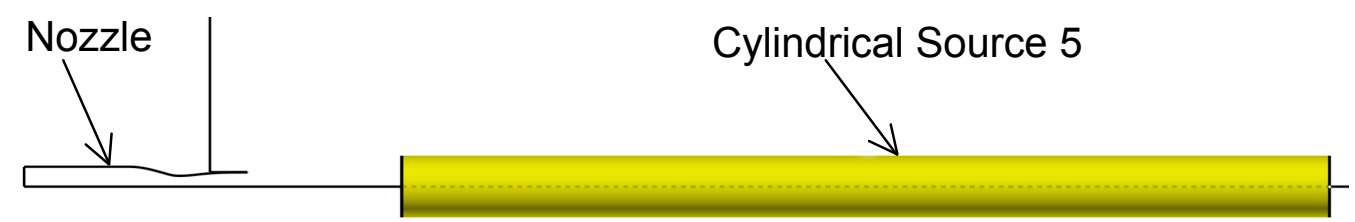

h) Cylindrical source 5 .

Figure 4. Seiner nozzle configuration and sourcing - concluded.

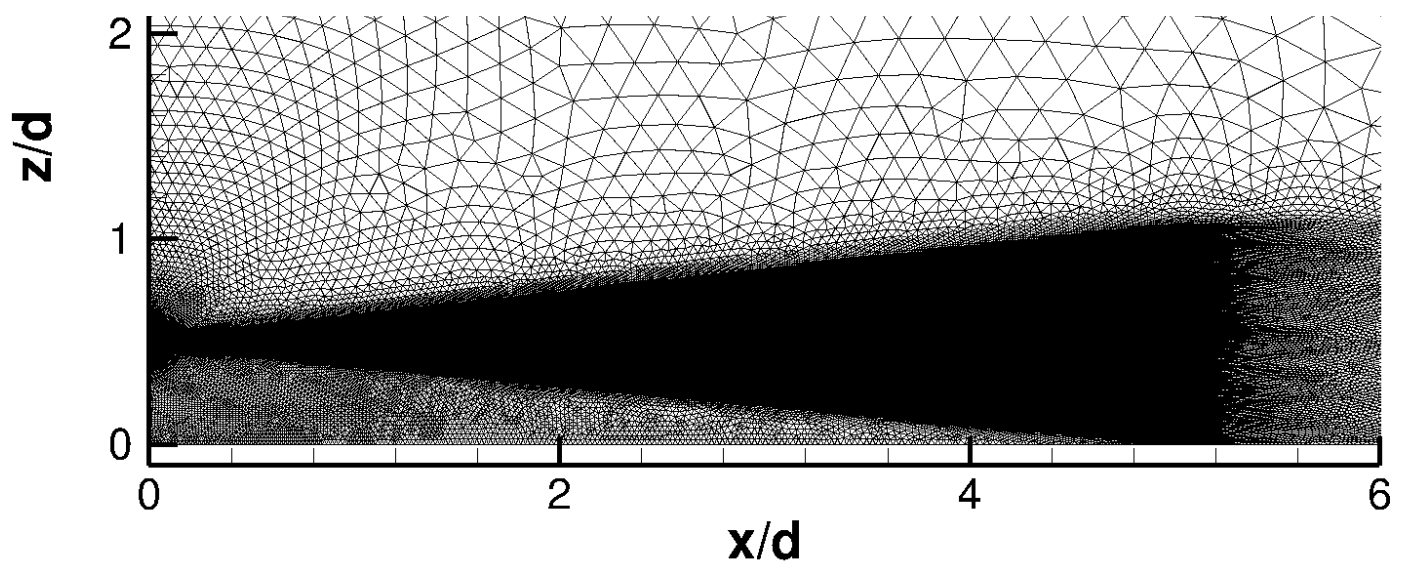

Figure 5. Grid in the symmetry plane for cylindrical source 4. 


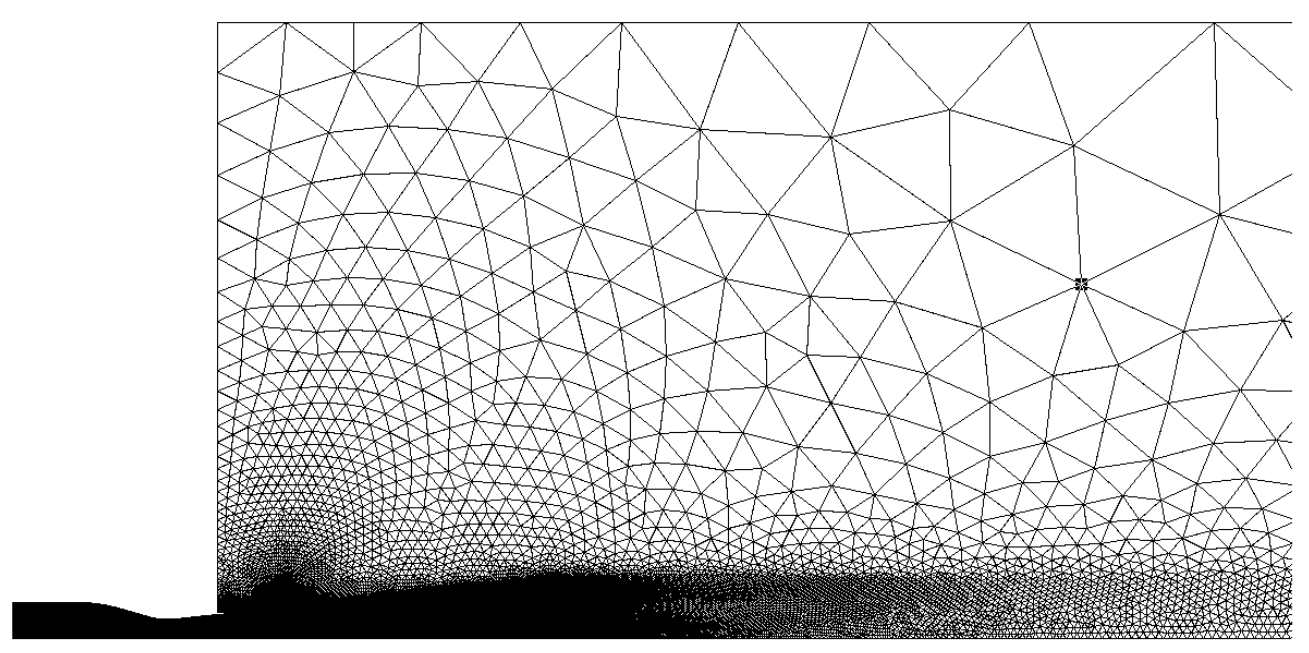

Figure 6. Computational grid for Seiner nozzle.

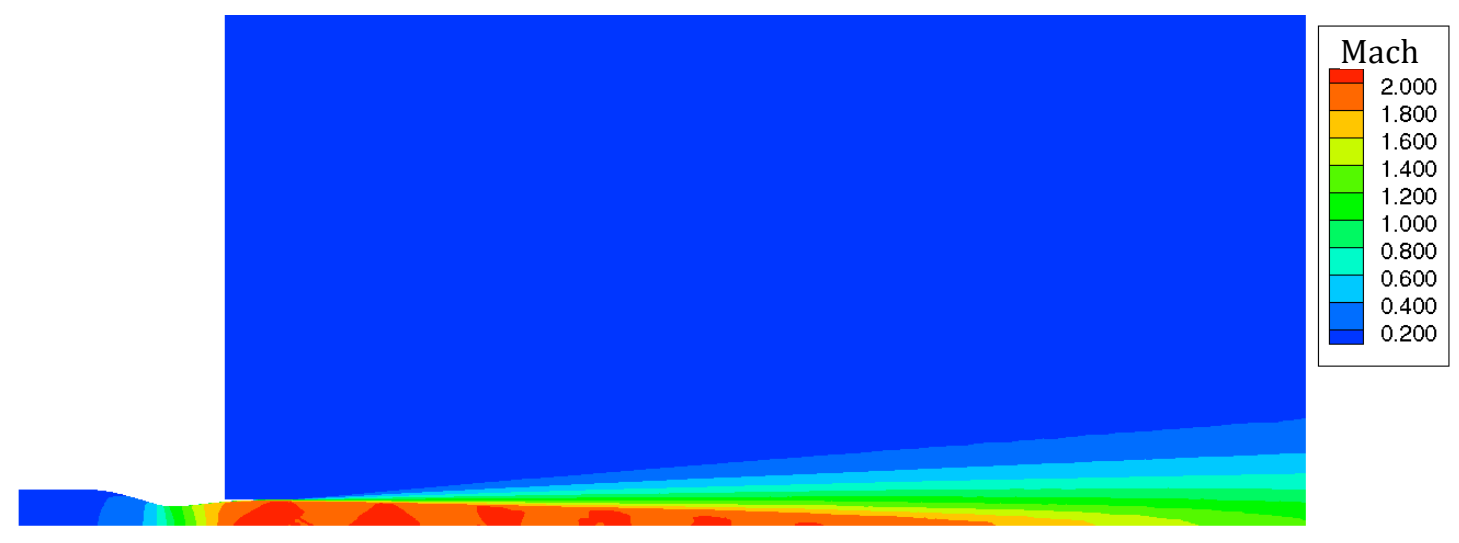

Figure 7. Mach profile for Seiner nozzle, nozzle exit Mach number $=\mathbf{2 . 0}, \mathrm{NPR}=\mathbf{7 . 8 2}$.

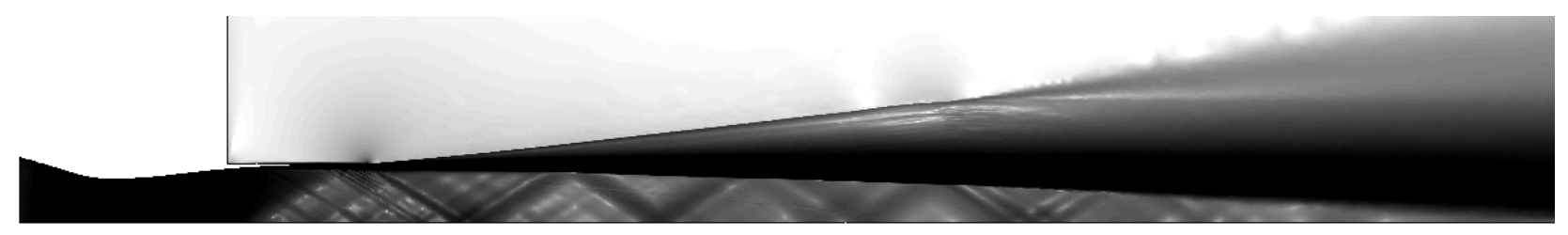

Figure 8. Density gradient view of Seiner nozzle, nozzle exit Mach number $=\mathbf{2 . 0}, \mathrm{NPR}=\mathbf{7 . 8 2}$. 


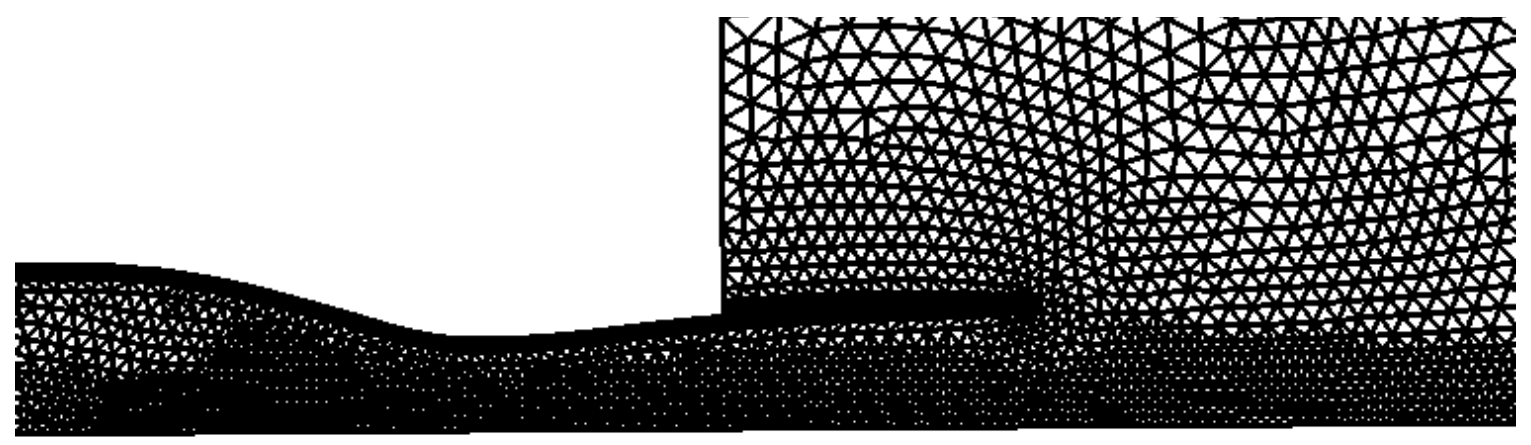

a) 2004 USM3D grid $^{6}, 85,817$ grid cells.

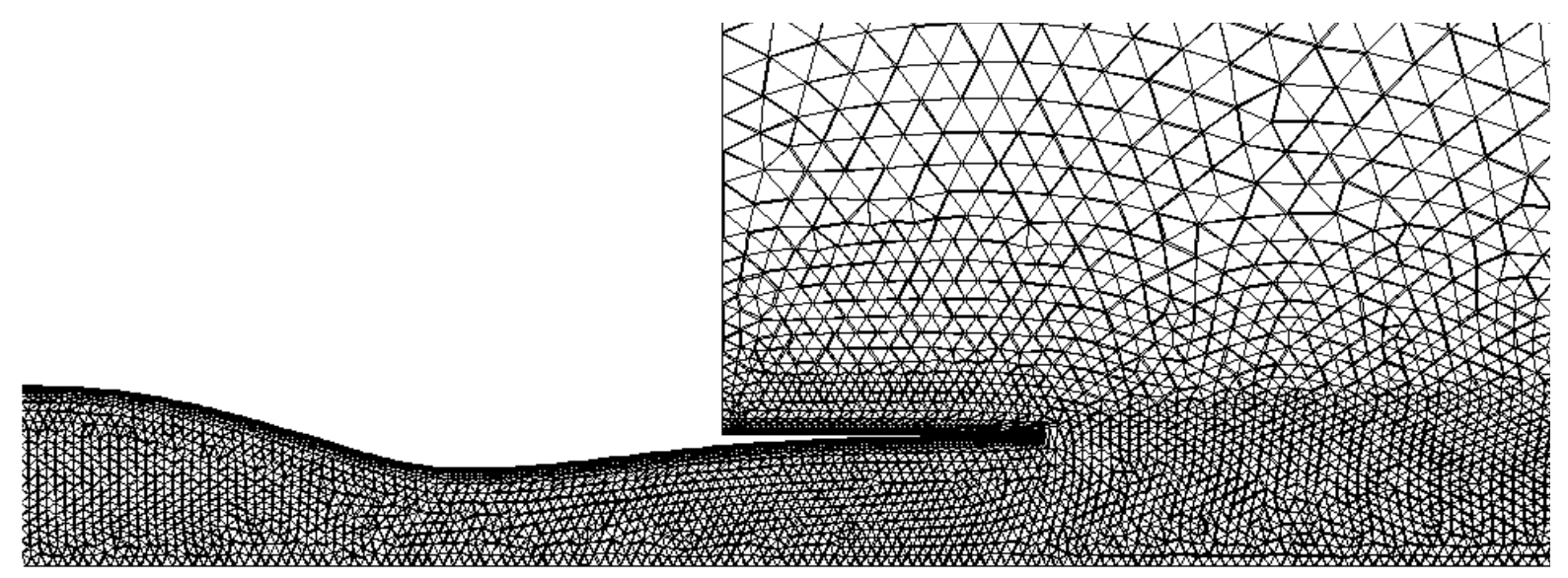

b) 2009 USM3D grid $^{7}, 300,750$ grid cells.

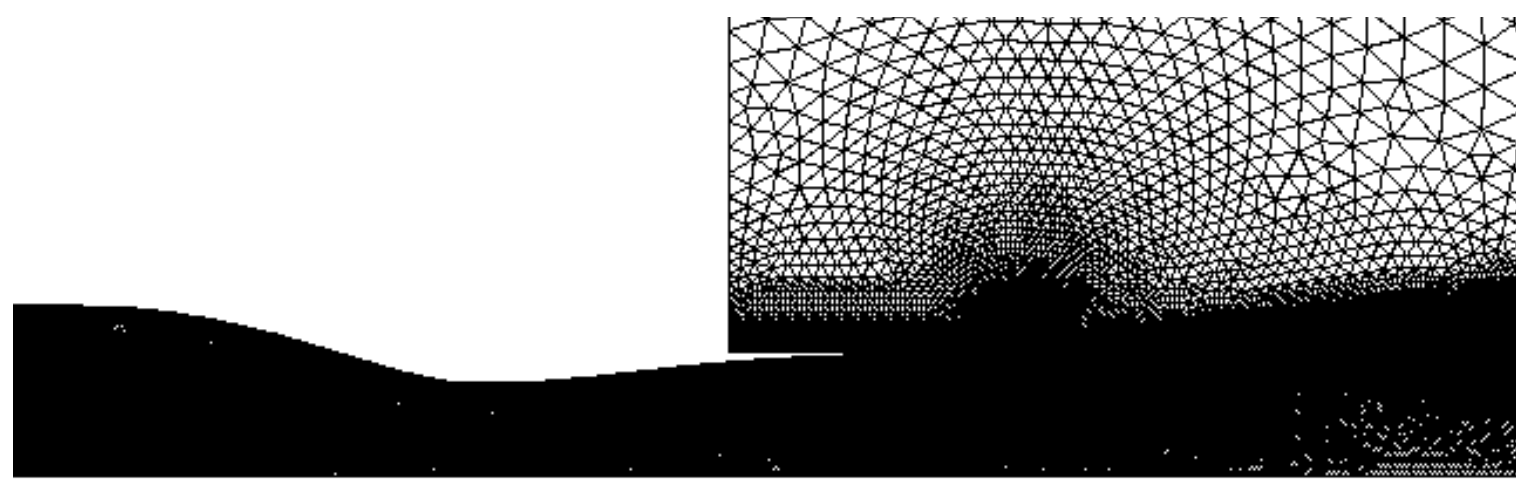

c) 2014 USM3D volume source grid, 814,145 grid cells.

Figure 9. Comparisons of Seiner nozzle USM3D grids. 


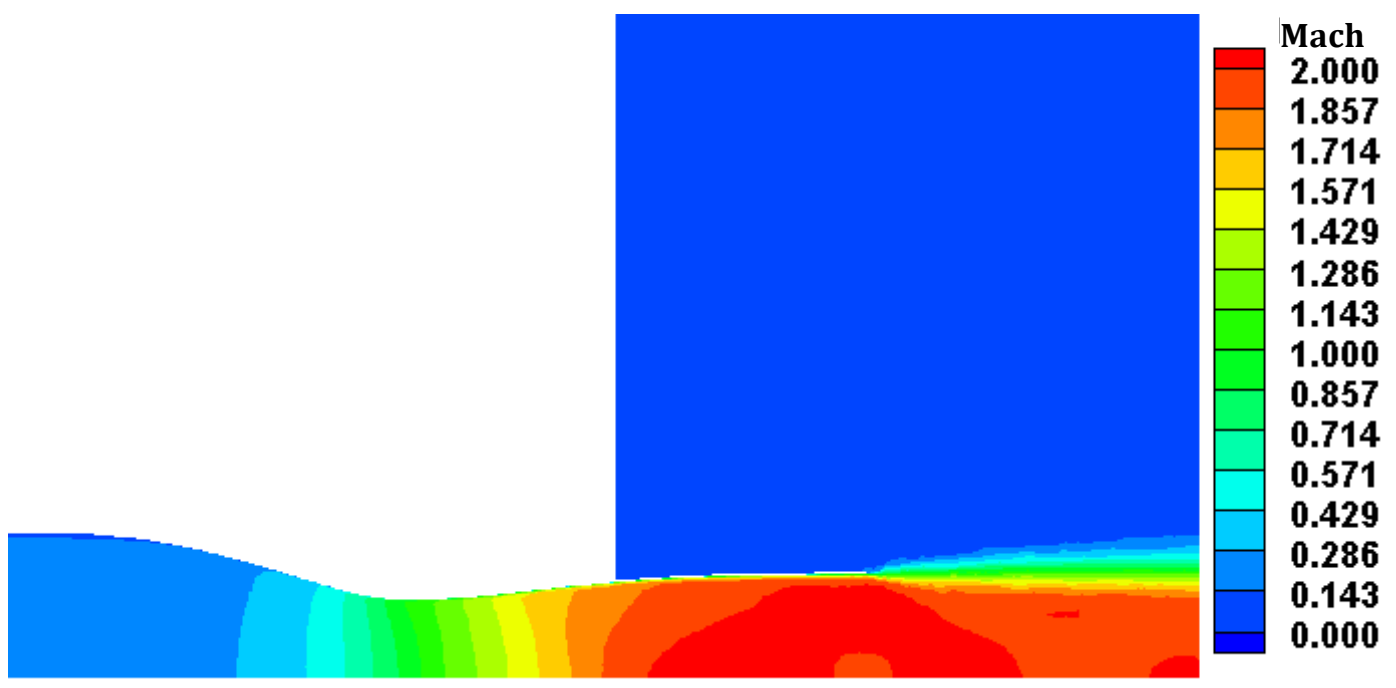

a) USM3D 2004 Mach profile with k- $\varepsilon$ turbulence model with Sarker's compressibility correction. ${ }^{6}$

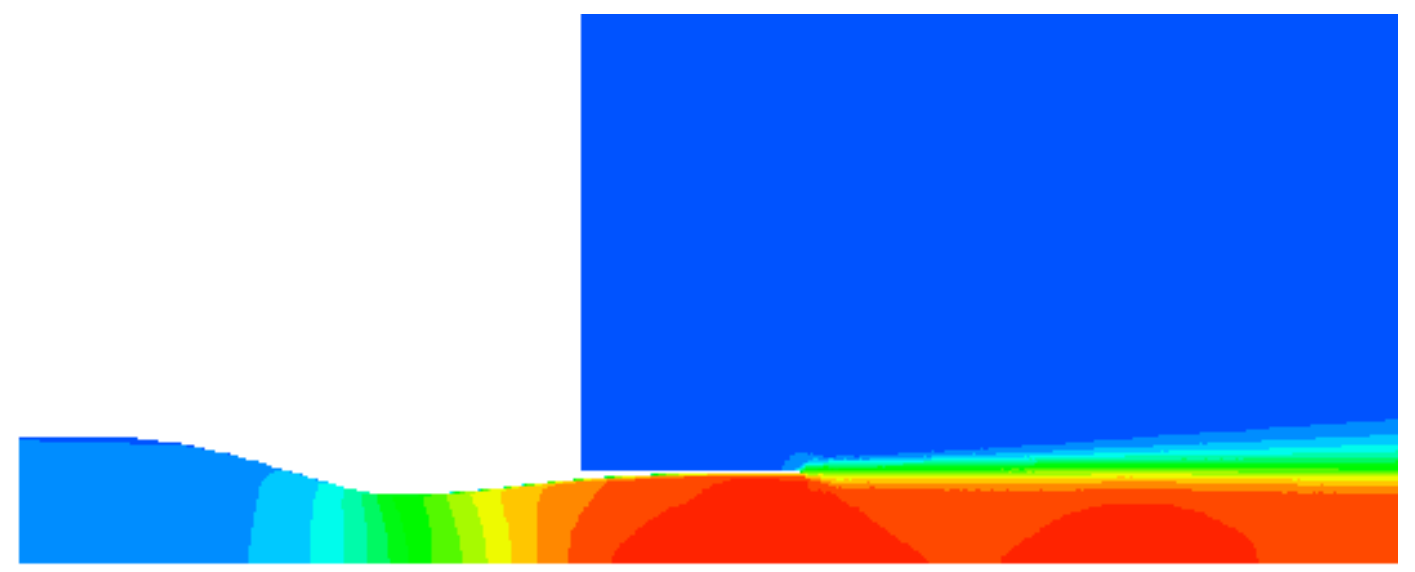

b) USM3D 2009 Mach profile with k- $\varepsilon$ turbulence model with enhanced Sarker's compressibility correction. ${ }^{7}$

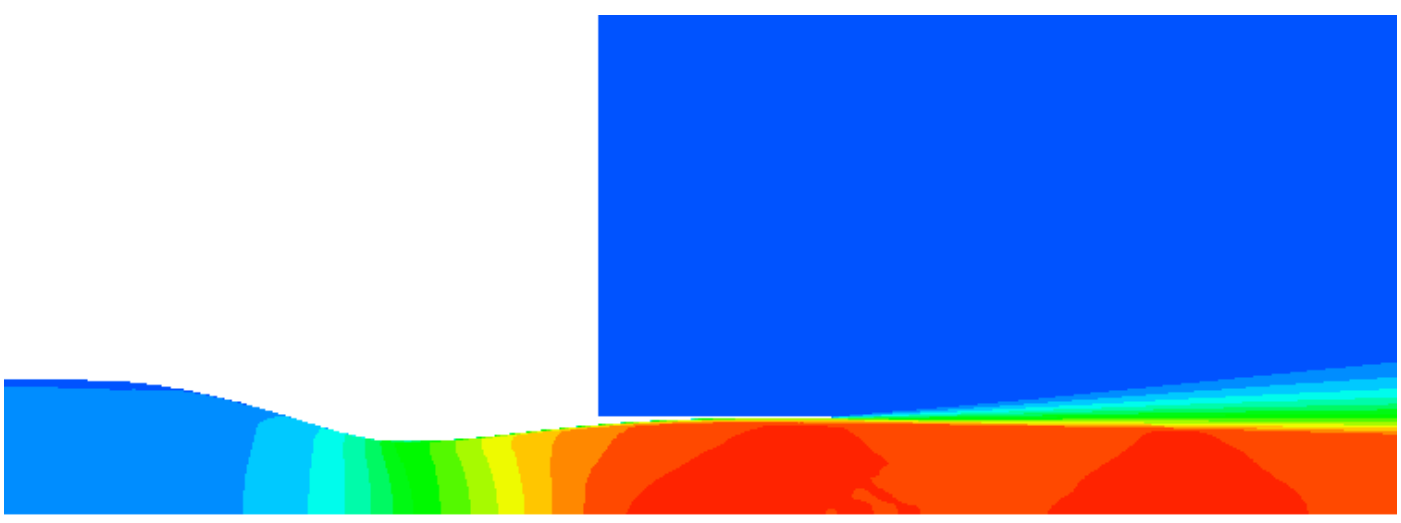

c) USM3D 2014 Mach profile with k- $\varepsilon$ turbulence model with enhanced Sarker's compressibility correction.

Figure 10. Comparison of Seiner nozzle USM3D Mach profiles, nozzle exit Mach number $=\mathbf{2 . 0}, \mathrm{NPR}=\mathbf{7 . 8 2}$. 12

American Institute of Aeronautics and Astronautics 


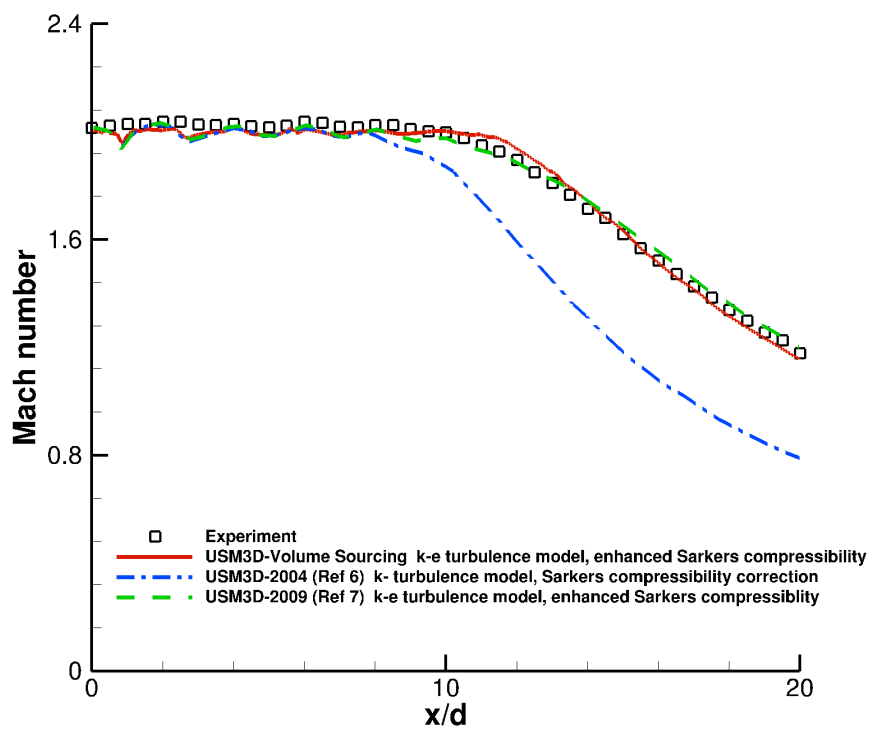

Figure 11. Comparison of Seiner nozzle USM3D centerline Mach distribution with experimental data, nozzle exit Mach number $=2.0$, NPR $=7.82$.

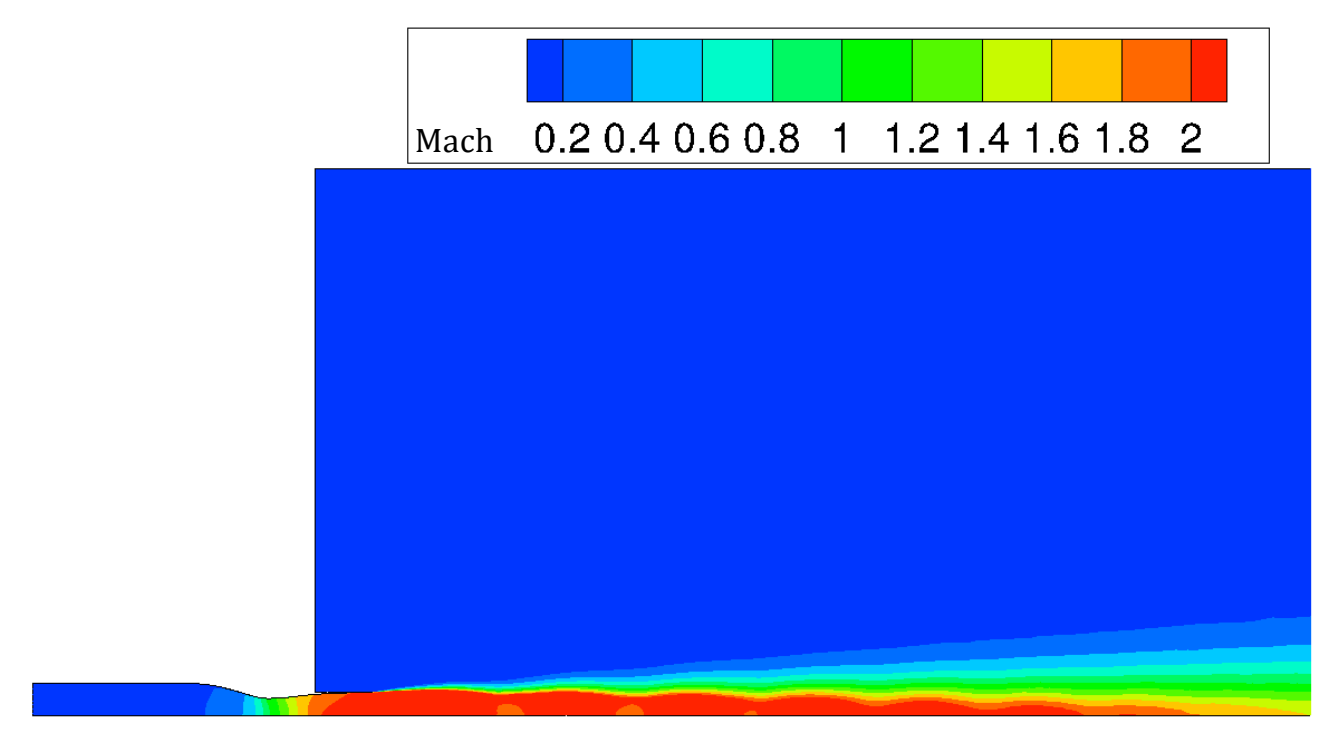

a) Full nozzle profile.

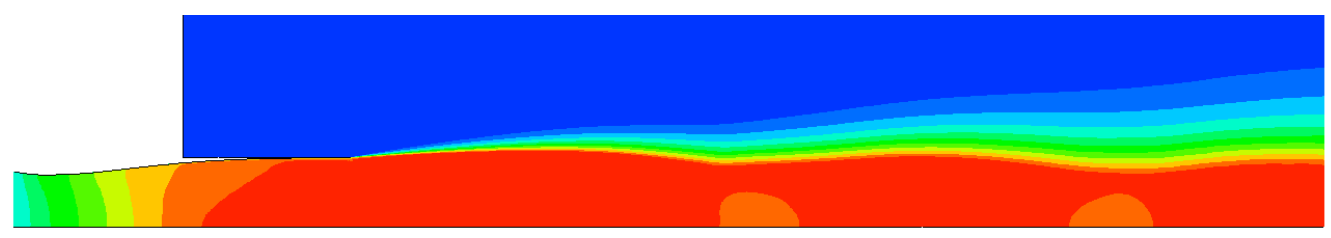

b) Close-up Mach profile.

Figure 12. USM3D Mach profile for under-expanded Seiner nozzle, nozzle exit Mach number $=\mathbf{2 . 0}$. 


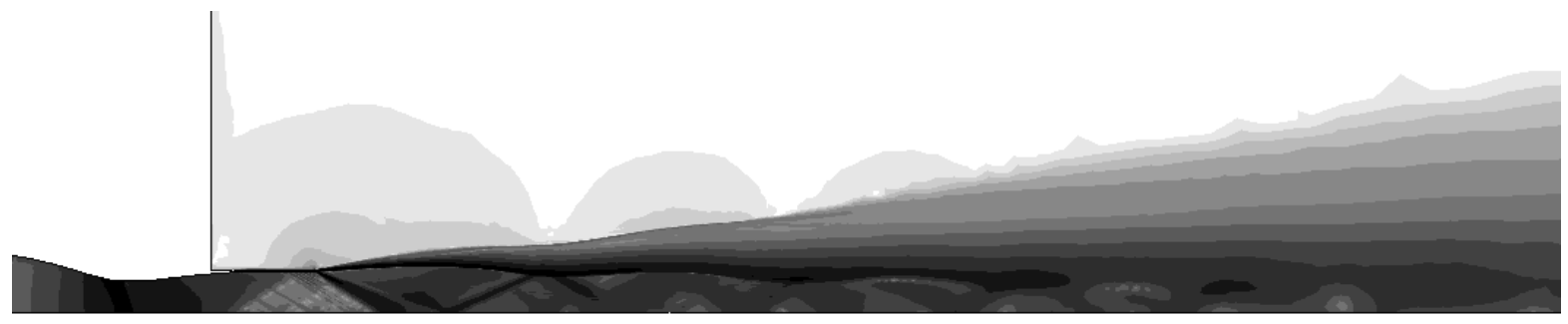

Figure 13. Density gradient view of under-expanded Seiner nozzle, nozzle exit Mach number $=\mathbf{2 . 0}$.

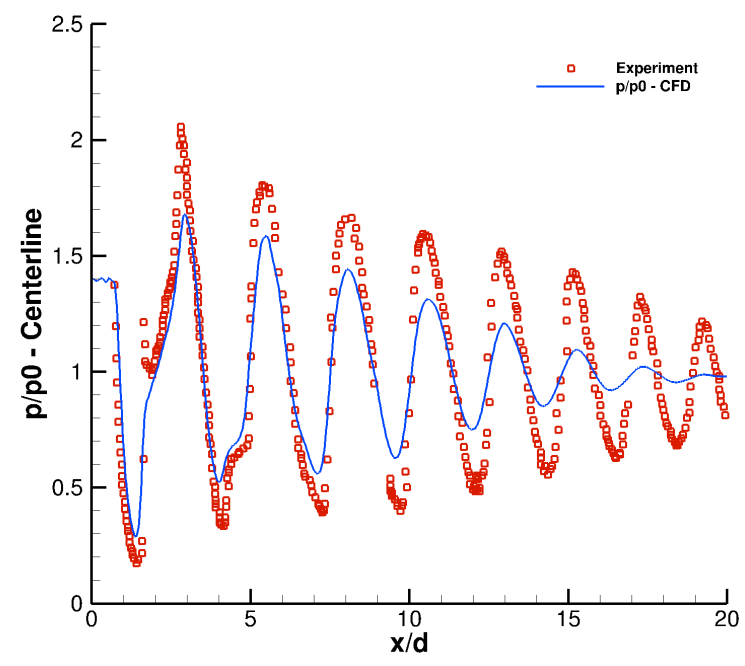

Figure 14. Comparison of under-expanded Seiner nozzle USM3D pressure profile with experimental data, nozzle exit Mach number $=\mathbf{2 . 0}$.

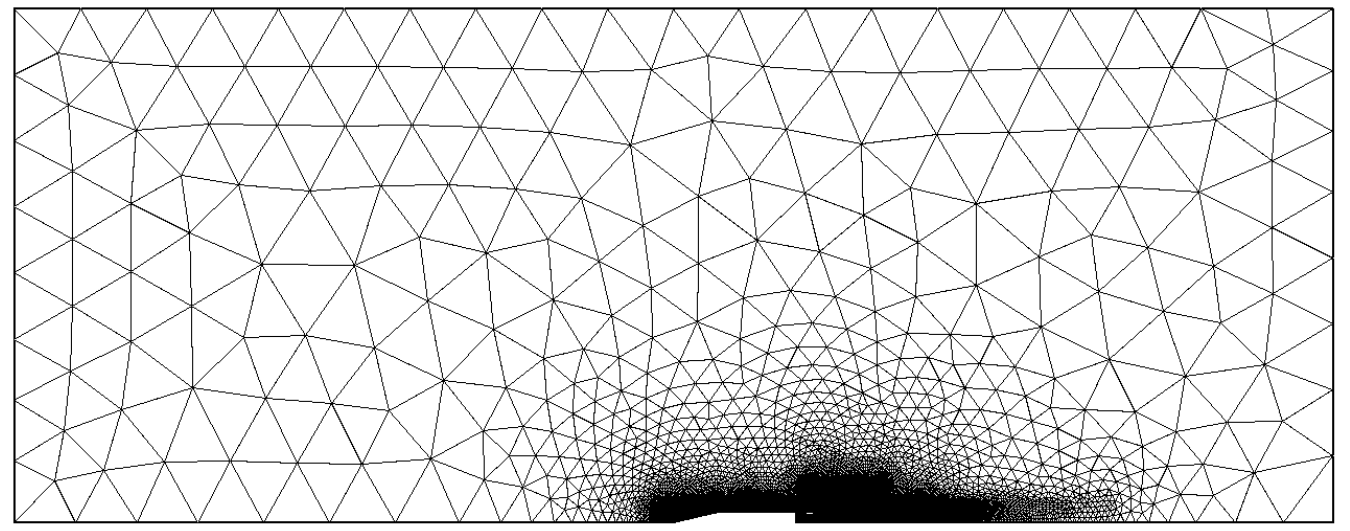

Figure 15. Putnam nozzle computational grid.

American Institute of Aeronautics and Astronautics 


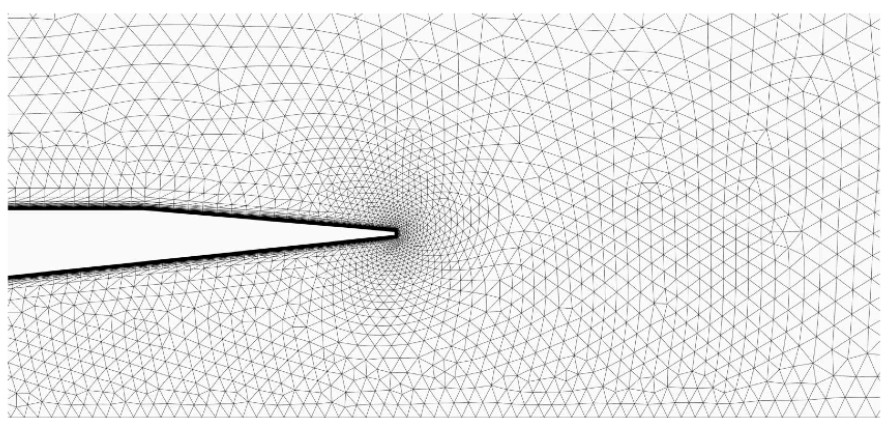

a) FUN3D original grid ${ }^{16}, \sim 315,614$ grid cells.

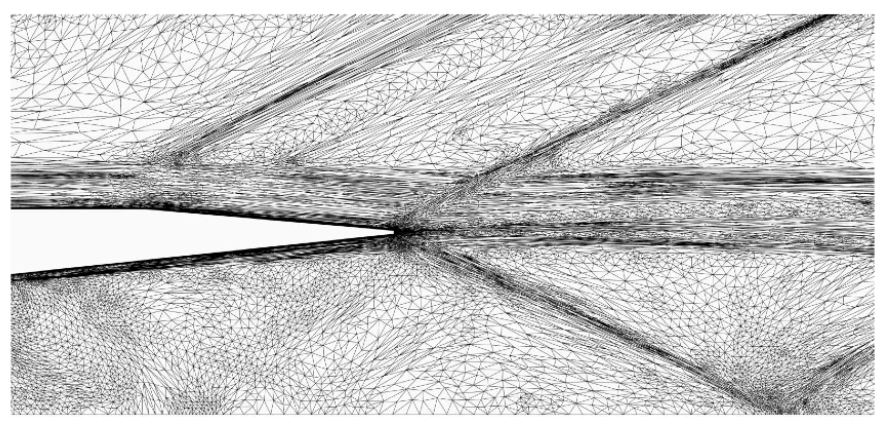

b) FUN3D adjoint grid ${ }^{16}, \sim 2,878,946$ grid cells.

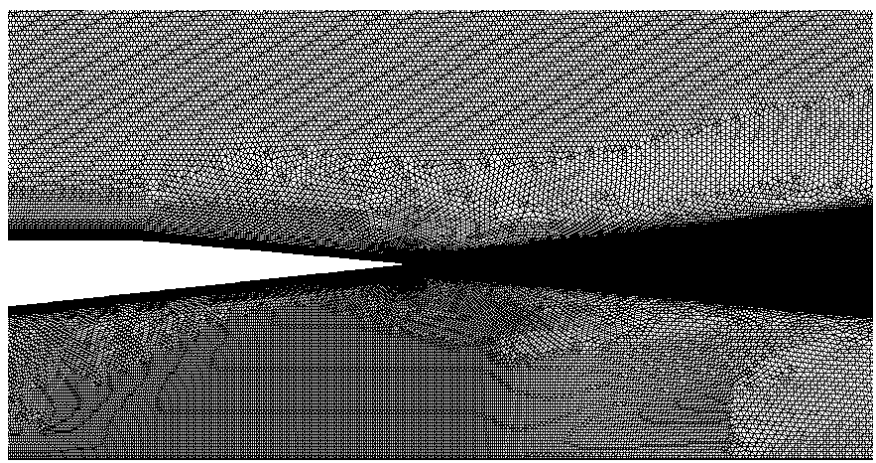

c) USM3D grid 1,259,430 grid cells.

Figure 16. Close-up of Putnam nozzle exit grids. 


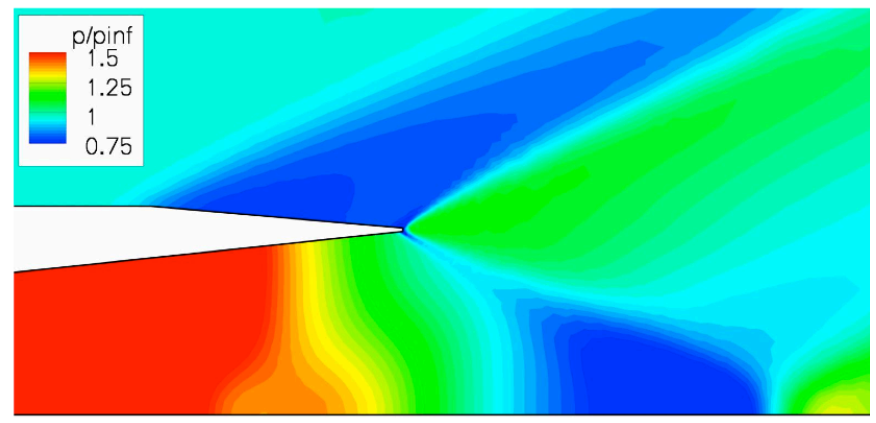

a) FUN3D original results. ${ }^{17}$

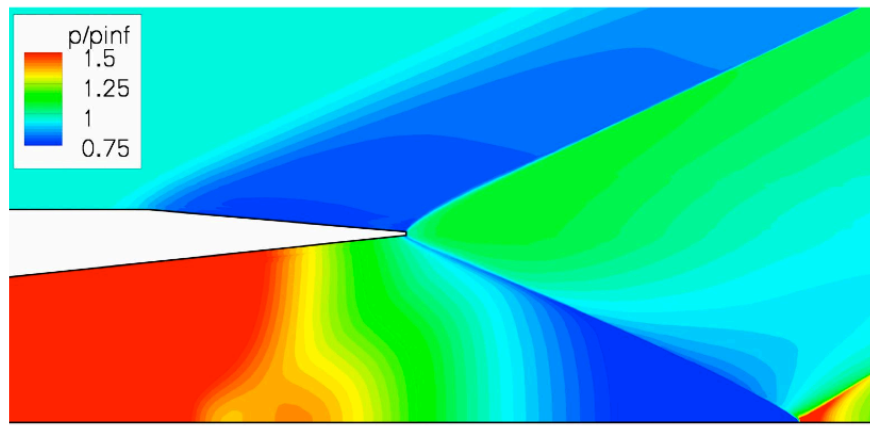

b) FUN3D adjoint results. ${ }^{17}$

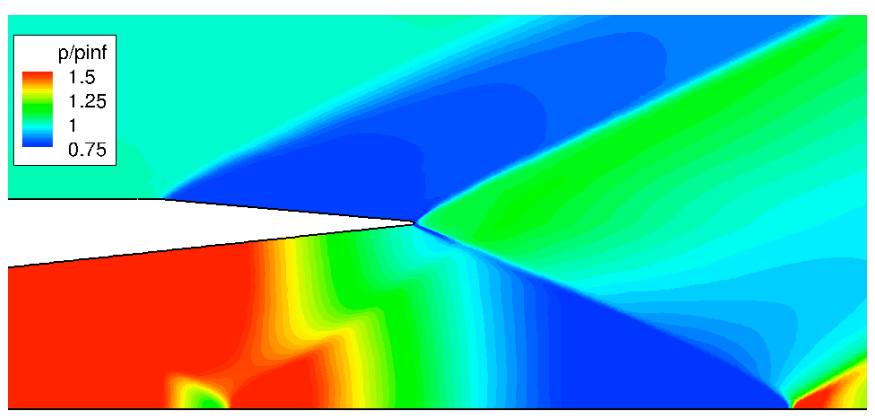

c) USM3D results

Figure 17. Close-up of Putnam nozzle flow, freestream Mach number = 2.2, NPR = 8.12. 


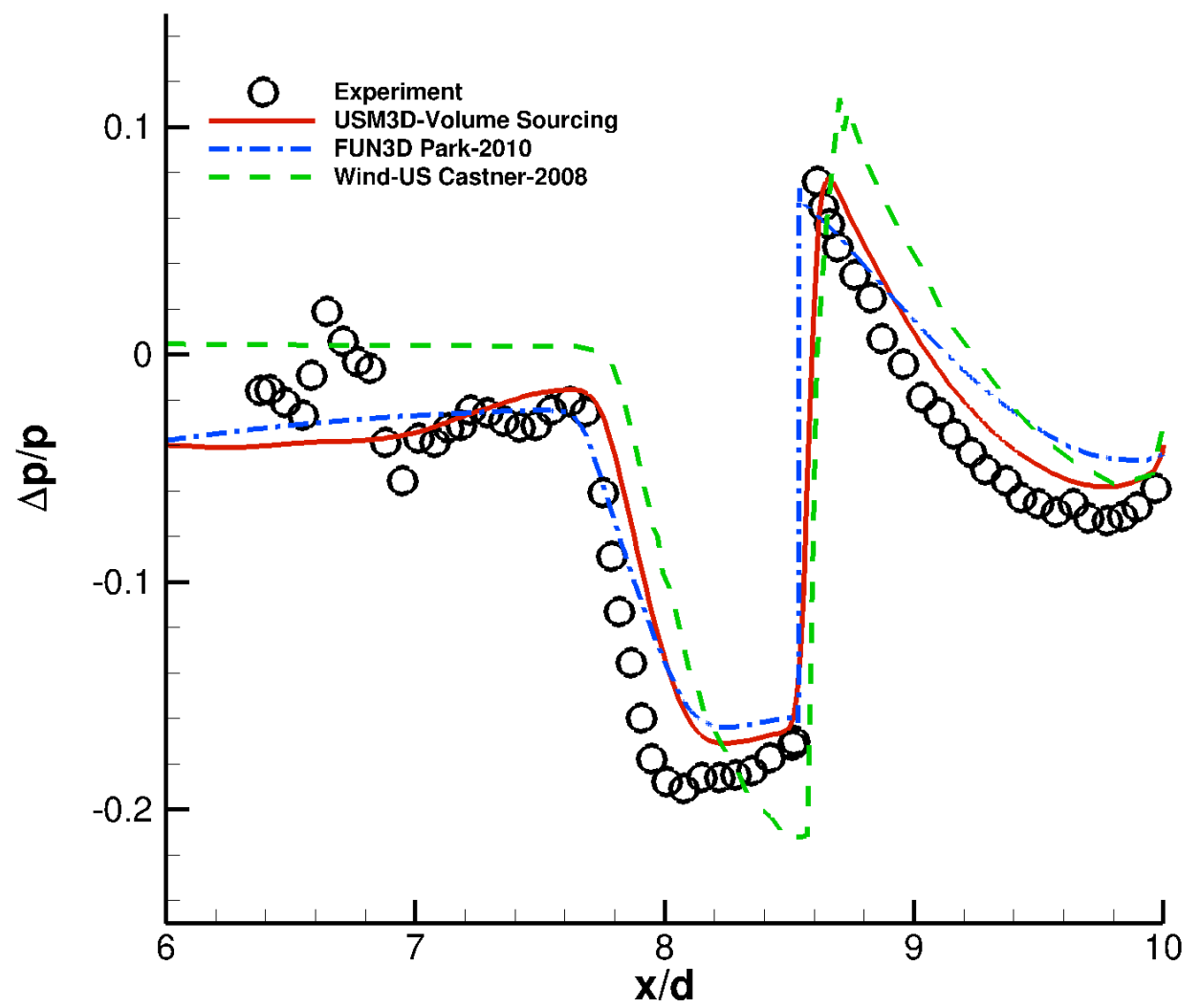

Figure 18. Comparison of Putnam nozzle CFD pressure profiles with experimental data, freestream Mach number $=2.2, \mathrm{NPR}=8.12$. 


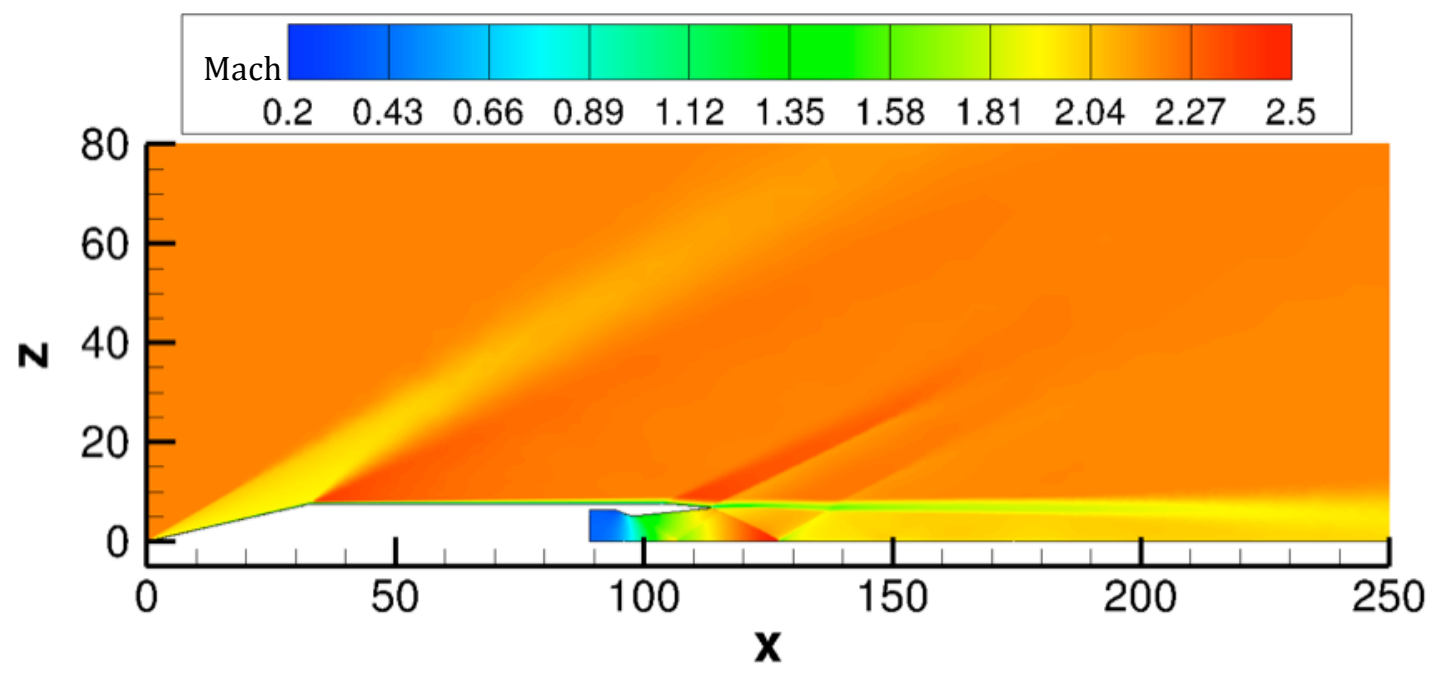

a) Mach profile.

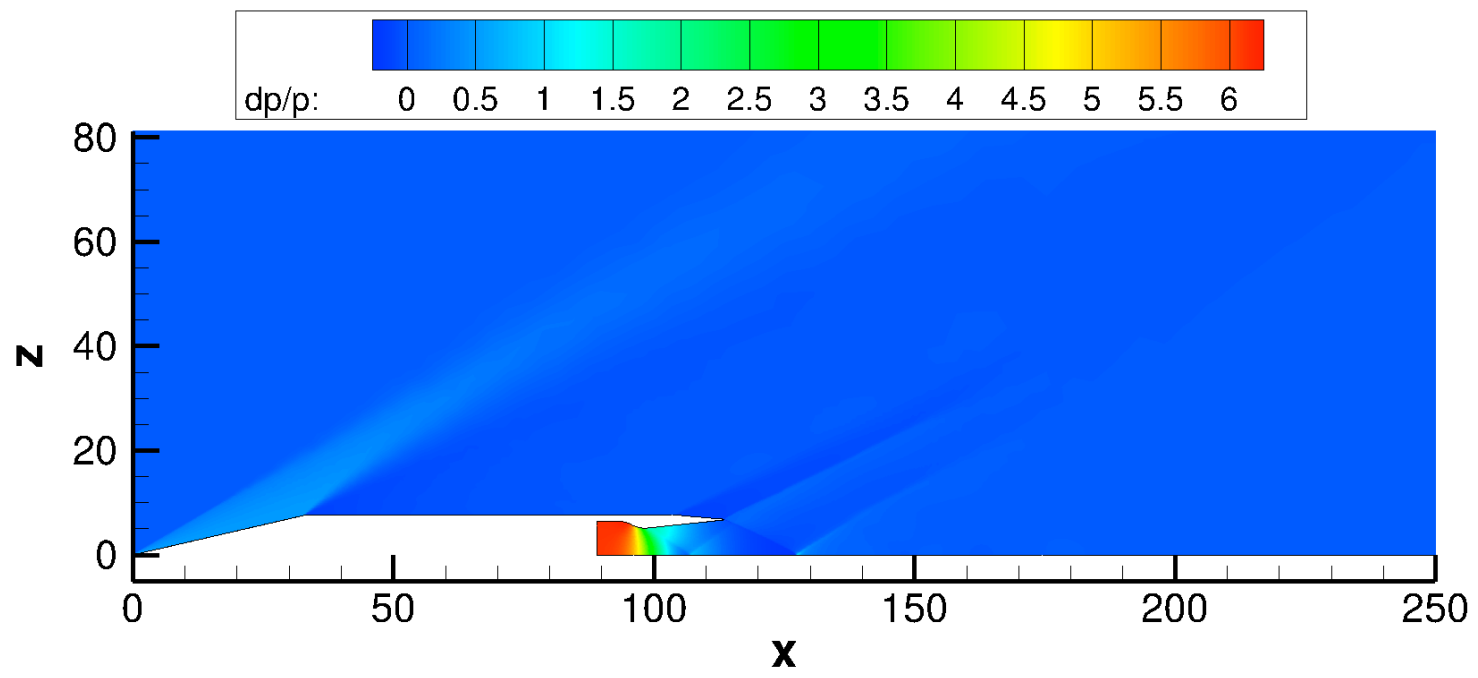

b) $\Delta \mathrm{p} / \mathrm{p}$ profile.

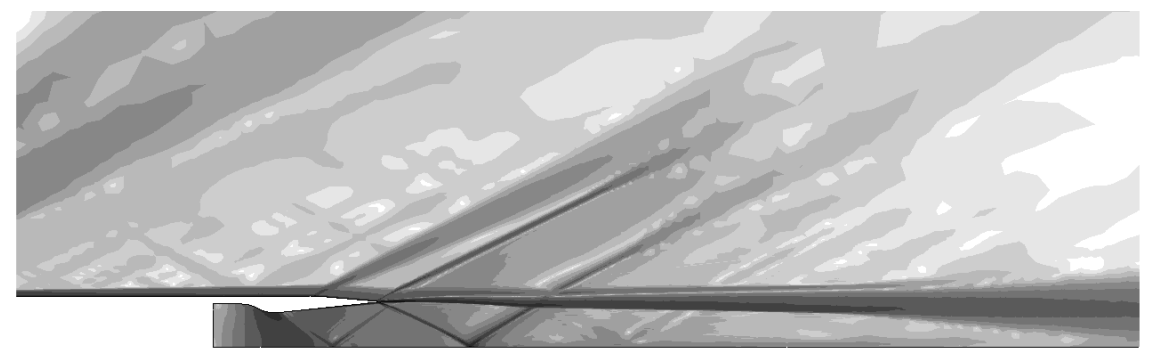

c) Density Gradient

Figure 19. USM3D CFD flow results for Putnam nozzle, freestream Mach number $=2.2, \mathrm{NPR}=8.12$. 